\title{
Team effectiveness: the predictive role of team identity
}

\author{
Daniela Pinheiro dos Reis \\ Tribunal de Contas da União, Salvador, Bahia, Brazil, and \\ Katia Puente-Palacios \\ Instituto de Psicologia, Departamento de Psicologia Social e do Trabalho, \\ Universidade de Brasilia, Brasilia, Brazil
}

\begin{abstract}
Purpose - The purpose of this study was to identify the explanatory power of the affective, cognitive and evaluative aspects of identity with work teams in predicting team effectiveness, represented by the variables: satisfaction with the team, manager-assessed team performance and objective indicators of performance.

Design/methodology/approach - Data were collected from 131 work teams of a Brazilian public organization with units in all state capitals of the country. Work team identity scale, the work team satisfaction scale, the team performance scale and objective performance indicators collected based on the achievement of the goals set for the units that make up the organization were used. To test the predictive model, three regressions were conducted using the stepwise method.

Findings - Regression analysis results showed that the evaluative dimension explains about $6 \%$ of the performance assessment given by managers, whereas the affective dimension explains $63 \%$ of the satisfaction with work teams. No significant results were found for the objective performance indicators.

Originality/value - The observed findings demonstrate the pertinence of understanding the work team identity as a collective and multidimensional phenomenon, as well as the contribution of its different components in explaining variables that represent effectiveness.
\end{abstract}

Keywords Work team identity, Identity with work teams

Paper type Research paper

\section{Introduction}

Among the strategies used by organizations to cope with the present-day production scenario, work teams are recognized for their problem-solving capacity and contributing to increased productivity. However, getting results from team building is not a simple task and requires an understanding of the elements involved in their operation. Through these elements, it is possible to identify the factors involved in the effectiveness of these performance units (Salas et al., 2015), as well as to combat the indiscriminate defense of the advantages that teams offer (Allen and Hecht, 2004a, 2004b).

The capacity of employees to work together is one of the main factors affecting the effectiveness of teams (Salas et al., 2015). Social identification, a process in which individuals recognize themselves and are recognized as members of a group, makes individuals share a vision

(C) Daniela Pinheiro dos Reis and Katia Puente-Palacios. Published in RAUSP Management Journal. Published by Emerald Publishing Limited. This article is published under the Creative Commons Attribution (CC BY 4.0) licence. Anyone may reproduce, distribute, translate and create derivative works of this article (for both commercial and non-commercial purposes), subject to full attribution to the original publication and authors. The full terms of this licence may be seen at http:// creativecommons.org/licences/by/4.0/legalcode 
RAUSP

54,2

of unity and a common future (Tajfel and Turner, 1979). When this process occurs in the context of work teams, it gives rise to work team identity. This type of identity promotes a collective perception that aligns individuals around team issues, making connection between employees more likely. Thus, identity with a work team is an important mechanism that unites employees around collective goals, and for this reason, can promote effectiveness (Gunlach et al., 2006).

Work team identity has been a subject of increasing interest in the organizational field (Miscenko and Day, 2016). Condensing a broad set of empirical findings, a meta-analysis concluded that this variable is related to various behaviors and attitudes at work (Riketta and Van Dick, 2005). Thus, it has been shown that individuals who identify highly with their respective teams are more willing to share knowledge and help colleagues (Ellemers et al., 2013). When compared with other targets of identity, it has appeared as the most intense and the best predictor of attitudes at work, such as satisfaction and organizational citizenship (Van Knippenberg and Van Schie, 2000), although there may be a cultural bias in these findings. Despite being considered a key factor in the functioning of teams, little effort has been expended toward more clearly understanding the relationship between work team identity and effectiveness criteria.

An important aspect in the study of this variable is the fact that work team identity is a shared attribute. The central point of the discussion is not in the group member's identification with the team, but in the sharing of the identity constructed by the group members in relation to the team to which they belong. The sharing has been considered a fundamental aspect in the understanding and the study of work team identity (Salas et al., 2015; Swaab et al., 2008). However, few studies use measurement strategies compatible with the collective essence of this variable, which in turn contributes to its disregard in the research on effectiveness (Ashforth et al., 2011).

Considering the need to better conceptualize work team identity, as well as to substantiate its predictive power as a group attribute, an empirical study was proposed with the central objective of verifying the contribution of work team identity in explaining the effectiveness of teams.

\section{Theoretical reference}

\subsection{Work team identity}

Work team identity originates in the literature focused on the identities constructed in the organizational context. The perspective of social identity, which basically comprises social identity theory - SIT (Tajfel and Turner, 1979) and self-categorization theory - SCT (Turner et al., 1987), is the most cited theoretical background among studies that seek to explain these phenomena. They have theoretical assumptions that are complementary and, for this reason, SIT and SCT will be considered as a single theoretical approach in the present research. These theories seek to explain the process in which individuals identify with particular groups. The central idea is that the groups are not elements external to the individuals; they can be internalized in the form of a social identity.

Social identity originates in a process called social identification. It is important to point out the differences between identity and identification. These terms, used interchangeably as a rule, have peculiarities that need to be highlighted (Ashforth et al., 2008). Identification is a process in which characteristics that define a person, group or object are internalized and come to integrate self-concept, thus being a mechanism pertaining to the individual. As a result of the identification process, identity is a description that provides answers to the questions "Who am I?" and "Who are we?" So, identification is the process, and identity its resulting structure. This structure can originate both in individual interpretations regarding 
the group and in socially constructed conceptions with respect to the group (Gunlach et al., 2006).

Social identity is conceptualized as that part of an individual's self-concept which derives from the knowledge of his membership in a social group together with the value and emotional significance attached to that membership (Tajfel and Turner, 1979). Along with the sense of belonging, the awareness of the value attributed to the group, in the social context and the emotional investment involved in the belonging to the group and AS WELL IN the evaluation of the group and the evaluation of the group are equally important elements in the characterization of social identity (Tajfel, 1982).

From this understanding, we argue that social identity is composed of the cognitive, evaluative and affective components (Ellemers et al., 1999). As social identity content, the cognitive component includes traits, beliefs, goals and other properties common among people belonging to a particular grouping. The evaluative part involves group judgments in the social context and their impact on the formation of group members' self-esteem. The affective component refers to the affective-emotional connection between the individual and the group. It represents the emotional investment in relation to one's awareness about belonging to the group and evaluations of the group. These three components are the key elements that guide and motivate the behaviors of the group members.

The cognitive, evaluative and affective components together represent the form in which social identity is manifested. By representing the extent to which individuals perceive themselves as members of the group, social identity and its components can be considered variables at the individual level. However, it is important to note that identity emerges as a social construct only when individuals begin to define themselves in terms of shared characteristics. Thus, it is possible to conclude that sharing is a central aspect related to the concept of social identity and, for this reason, must be considered in the discussions that involve this construct.

Sharing arises when people come to have similar interpretations, to a greater or lesser extent, around a common scenario. This happens because people being grouped together use it to construct meanings about events experienced as a group. The composition model called direct consensus argues that phenomena conceptualized and operationalized at the lower level can emerge in a functionally similar manner at the higher level through intragroup consensus (Chan, 1998). The transformation of individual attributes into collective attributes is known as emergence, a process that seeks to explain how the dynamic articulation of the individual's own elements gives rise to the emergence of a collective attribute (Kozlowski and Klein, 2000). From these theoretical contributions, we argue that social identity is a shared and collective structure that comes from the identity constructed between the individuals and the group to which they belong, and emerges as a result of the experiences in common and the exchanges of interpretations between the members of the group.

Considering sharing as a fundamental aspect of social identity, the model of social identity construction in small groups argues that the structuring of social identity follows a continuum that ranges between the deductive and the inductive process (Postmes et al., 2005). In the identity formed purely by the deductive process, this initiates from a preexistent category in the social context. Through intergroup comparison, the differences between groups are accentuated and the similarities minimized, contributing to the construction of a social identity. The intergroup context would be the main factor responsible for the appearance of this construct. On the inductive side, the contributions provided by each member are inputs for the emergence of social identity. By discussing individual points of view about situations that occur in the group context, people would 
RAUSP

54,2

develop a common understanding of the representative attributes of the group. In this case, social identity can be understood as a collectively constructed structure characterized by the convergence of group members around a norm or any other attribute that represents the group. This model reinforces the idea of social identity as a shared construct in which intergroup context and interaction would be the main factors that facilitates the emergence of this phenomenon.

Social identity can derive from the participation in differents types of groupings and its formation varies according to the attributes of each grouping (Van Knippenberg and Van Schie, 2000). Organizational identity, for example, would be a macro structure, representing the organization as a whole. Work team identity would be a mesostructure, relative to intermediate segments. The present study aims to investigate how this feeling is manifested in the context of workteams.

Work teams are a specific kind of groups that can be described as a set of three or more people who undertake complementary activities, have shared work goals, maintain interdependent relationships and, mainly, identify and are identified as members of one single team (Hackman, 1987). Applying the processes of social identity construction to work teams, we argue that work team identity is the extent to which the work team is incorporated into the self-concept (Gunlach et al., 2006). The importance of this type of identity lies in the way the individuals recognize themselves as members of a group and attribute to themselves the characteristics specific to that entity.

By representing the extent to which individuals perceive themselves as members of the group, work team identity and its components have been conceptualized and analyzed as an attribute representative of the individual. However, depending on the way it is analyzed, work team identity can also be considered as a collective phenomenon. This interpretation stems from the analysis of situations and processes specific to small groups. The members of a particular social group, when discussing points of view about situations that occur in their immediate setting, tend to share thoughts, beliefs and interpretations about different subjects, including about the results of the identification process. In interacting and exposing their interpretations regarding the work team, these individuals would tend to develop a common understanding of who they are as a collective entity, turning what was an individual's own attribute into a collective structure, representative of the team itself, and not only of its members (Ashforth et al., 2011). Although different, the individual and collective forms are reciprocally connected, such that the identification of the individual with the group favors the emergence of an identity of shared construction, and this in turn shapes the individual's group identity.

Given the arguments presented, the present work argues that work team identity is a multidimensional construct, composed of cognitive, evaluative and affective components. Owing to sharing, it can be considered a collective phenomenon, representative of the work team, located at the meso level of analysis.

\subsection{Work team identity and effectiveness}

Work team effectiveness can be considered the focus of the literature on the functioning of work teams (Salas et al., 2015). In practice, team effectiveness measurement requires objective parameters to be accurately captured. The model proposed by Hackman (1987) is one of the most frequently used in this area of research. It adopts three criteria to measure effectiveness. The first of these refers to the affective reactions related to work experiences. In this sense, the group's activities should satisfy, rather than frustrate, the personal needs of its members. Among the indicators of an affective character, satisfaction is highlighted. The second criterion is focused on viability, related to maintaining the team as a unit. The 
third and last criterion is group performance, represented by objective indicators and by subjective assessments. The objective indicators translate, by quantitative data, team productivity. The subjective assessment measures of performance are judgments made by internal or external evaluators of the group. They can be the members themselves, or external or internal clients, such as the managers responsible for the team. Satisfaction and performance are widely used constructs in research aimed at the effectiveness of work teams.

Satisfaction concerns the positive emotional state resulting from a job or from work experiences (Siqueira and Gomide, 2014). The studies involving satisfaction and work team identity show positive relationships between these phenomena. When compared with other targets of identity, work team identity is strongly related to work satisfaction (Johnson et al., 2006; Van Knippenberg and Van Schie, 2000). The affective component is mainly responsible for this relationship (Johnson et al., 2012). Studies that discuss the way in which the identities built in the organizational context are related to different variables suggest that these relationships depend, among other factors, on the level of correspondence between the variables (Van Dick et al., 2004). According to these studies, work team identity is more intensely related to work team satisfaction, whereas organizational identity is more intensely related to satisfaction with the organization.

Based on this understanding, we assumed that the analysis of the relationship between work team identity and satisfaction would be clearer if we specifically considered work team satisfaction. As the level of analysis is a neglected aspect in research of this nature, the present work intends to evaluate how this relationship occurs at the meso level. In view of the arguments presented, the following research hypothesis was formed:

H1. The affective component of work team identity is the main predictor of work team satisfaction.

Team performance is focused on the execution of activities related to collective goals (Salas et al., 2015). In studies that seek to analyze the relationship between team identity and performance in natural teams, the individual is often the unit of analysis used and identity is conceived as a one-dimensional construct, disregarding important elements such as affective and evaluative aspects (Solansky, 2011).

Prior research suggests that the relationship between team identity and performance may not be direct but mediated by other variables (Ellemers et al., 2013). However, there are indications that the direct relationship between these variables is more likely when the group members recognize a shared identity (Swaab et al., 2008).

Based on the assumptions of SIT, we argued that the evaluative component of social identity is the main predictor of team performance. The evaluative component of social identity includes the impact of the group's judgments on the development of self-esteem. According to this theoretical assumption, people seek to maintain and increase a positive self-esteem, and part of this is determined by belonging to groups, called group self-esteem (Tajfel and Turner, 1979). As group self-esteem is made by comparisons with relevant groups as a parameter, and performance is a comparison criterion that defines social status and prestige within an organization, we argue that individuals who identify highly with the group would be willing to undertake efforts to achieve collective goals. This would be so because the group's success in attaining goals increases prestige and respect, affecting selfesteem. The evaluative component would have increased predictive power by being shared among team members. From these arguments, the following research hypotheses are defined: 
RAUSP

54,2

H2. The evaluative component of work team identity is the main predictor of the objective performance indicator.

H3. The evaluative component of work team identity is the main predictor of team performance, as assessed by the manager.

\section{6}

\section{Method}

\subsection{Sample}

This research was conducted in a federal public organization with units in all state capitals of the country. Its structure is divided into specialized departments, organized by common assignments. It should be noted that the activities of this organization are performed, primarily, by work teams, in which each set of workers receives a series of activities, whose completion is only possible when each member performs their part of the assignment.

Work teams were considered to be units having an immediate supervisor and subordinates, whose work goals are shared and who have collective responsibility for the goals reached. To participate in the sample, each team needed to have as respondents the manager and at least two members.

The sample of 498 employees, distributed in 131 work teams, participated in the study. Of this total, 367 were members of work teams and 131 were immediate supervisors. Regarding the nature of the sample, the group of respondents was between 19 and 70 years of age $(M=41.12$; $\mathrm{SD}=9.36)$, the majority, 65.5 per cent, being male.

\subsection{Instruments}

To verify the adequacy of the proposed predictive model, the data were collected using the work team identity scale (Reis and Puente-Palacios, 2016), the work team satisfaction scale (Puente-Palacios and Borges-Andrade, 2005) and the team performance scale (PuentePalacios et al., 2016b). Two questionnaires were administered. One of them was completed by the team members and included the work team identity and the work team satisfaction scales. The second questionnaire was completed only by the immediate supervisor and consisted of the perceived performance scale.

In addition, objective performance indicators (secondary data) were collected based on the achievement of the goals set for the units that make up the organization. Institutional plans established the institution's goals. An operational plan details the goals of each work team and establishes ways to calculate the goal achievement results. The use of indicators portrays how this body verifies whether its performance is succeeding and whether it is delivering the expected results. These scores could range between 0 and 150 points and have been measured on a quarterly basis by the organization. These data were provided by the organization itself.

\subsection{Data collection procedures}

Data collection was conducted over two months, through a system developed especially for this research. All employees of the organization who worked in teams were invited to participate. The invitation was made through a personal message containing information about the origin and the objectives of the research, and a link to access the specific questionnaire. 


\subsection{Data analysis procedures}

As for the data analysis, exploratory factor analyses and extraction of internal reliability indexes to verify the psychometric properties of the work team identity, work team satisfaction and team performance scales were first conducted. As the data were collected at different levels (individual and team), it was necessary to equalize the levels of analysis to the meso level. The direct consensus model (Chan, 1998) was used to characterize work team identity and work team satisfaction as collective attributes. This model uses the intragroup consensus to explain the way in which conceptualized and operationalized constructs at the individual level appear in a functionally isomorphic way at the collective level. The guidelines provided by authors who study emergence processes (Chan, 1998; Kozlowski and Klein, 2000, Puente-Palacios et al., 2016a) endorse the use of the arithmetic mean of the team members' individual scores as representative of the collective attribute, as long as intragroup homogeneity and intergroup heterogeneity are demonstrated.

Intragroup homogeneity was verified by analyzing average deviation relative to the median $\left(\mathrm{AD}_{\mathrm{Md}}\right)$. The $\mathrm{AD}_{\mathrm{Md}}$ allows evaluation of the degree of heterogeneity of the responses, so that values below the cutoff established by the formula $c / 6$, where $c$ corresponds to the amplitude of the scale, demonstrate a high degree of consensus (Burke and Dunlap, 2002).

Intergroup heterogeneity was assessed based on the calculation of the intraclass correlation coefficient (ICC) and one-way analysis of variance (ANOVA). The ICC is an indicator that compares intragroup and intergroup variance and reports the magnitude of the intergroup. The interpretation of the ICC results is based on studies in the organizational behavior field that identify ICC values between 0.12 and 0.15 as indicators of sufficient variance between groups (Bliese et al., 2007). The one-way ANOVA calculation sought to verify the existence of statistically significant discrimination between the teams participating in the research.

To test the predictive model, three regressions were conducted using the stepwise method. The use of this method is based on the need to obtain empirical evidence of the greater predictive power of some of the identity dimensions, as asserted in the hypotheses of this study. Each predictive model had the three work team identity factors as independent variables and one of the effectiveness criteria defined for the present study as the dependent variable: work team satisfaction, performance evaluated by managers and objective performance indicators.

\section{Results and discussion}

The objective of the present study was to identify the contribution of the affective, cognitive and evaluative aspects of work team identity, as a collective phenomenon, to team effectiveness. Satisfaction and performance were the criteria adopted to measure effectiveness. First, the scales' psychometric properties will be presented, then the process of data aggregation to the team level and, finally, the predictive model test results.

Before proceeding to the factor analyses, an exploratory analysis of the data was conduced. Regarding sample size, it was verified that the relation between number of subjects and items was higher than 10, which makes it appropriate for conducting factor analysis. Normal distribution of the responses was verified by calculating asymmetry, taking the recommendations of Miles and Shevlin (2001) as a guideline. According to them, absolute values above 2 denote serious violations of normality. The results showed values below 2 , demonstrating that the normality assumption had been met.

As the preliminary data authorized the use of factor analysis, we verified the psychometric properties of each instrument used. The work team identity scale has 20 items capable of explaining 65.33 per cent of the variance. Consistent with the theoretical 
RAUSP

54,2

framework adopted, the exploratory factor analysis pointed to the existence of three factors. The first one has nine items, whose content portrays the degree of emotional involvement between the individual and the group, compatible with the affective dimension of social identity. The factor loadings of the items were between 0.95 and $0.49(\alpha=0.92$ and item-total correlation $=0.75)$. The second factor contains seven items with factor loadings between 0.93 and $0.73(\alpha=0.91$ and item-total correlation $=0.73)$. The content of these items shows how much the team members perceive themselves in a similar way to their colleagues and to the group. This corresponds to the cognitive dimension of social identity. The third factor has four items with factor loadings between 0.99 and $0.48(\alpha=0.82$ and item-total correlation $=0.59$ ). These items capture the way in which members assess the group itself and perceive the assessment made by individuals outside the group, which corresponds to the evaluative aspect of social identity.

The work team satisfaction scale has a single-factor structure and an explained variance of 66.70 per cent. It is composed of five items with factor loadings between 0.87 and $0.76(\alpha=$ 0.91 and item-total correlation $=0.58$ ). The team performance scale is also single factor and explained 44.66 per cent of the phenomenon. This measure consists of nine items whose loadings range between 0.74 and $0.47(\alpha=0.88$ and item-total correlation $=0.58)$. All the factor solutions were obtained using the Principal Axis Factoring method. From the results presented here, it can be stated that the validity and reliability indexes found in the work team identity, work team satisfaction and team performance scales attest to the appropriateness of these instruments for the sample in this study, which supports the use of their results in the predictive model analysis.

The information related to work team identity and team satisfaction was collected at the individual level. As the research model posits the occurrence of relationships between mesolevel variables, it was necessary to verify the possibility of aggregating the individual responses to compose group scores, through intragroup homogeneity and intergroup heterogeneity analysis.

Intragroup homogeneity was investigated using the $\mathrm{AD}_{\mathrm{Md}}$ calculation, as previously stated. Cases that presented $\mathrm{AD}_{\mathrm{Md}}$ values above the cutoff established by the formula $c / 6$, where $c$ corresponds to the amplitude of the scale, do not demonstrate intragroup homogeneity (Burke and Dunlap, 2002). For the present study, in which the variables under analysis were assessed on five-point Likert scales, the reference value is 0.83 . Thus, teams with $\mathrm{AD}_{\mathrm{Md}}$ values above 0.83 did not attain the minimum degree of consensus required to characterize the sharing of interpretations. Among the 131 teams that participated in the research, 29 did not attain the minimum degree of consensus needed to identify the sharing of interpretations among group members. This first finding reveals that the 29 sets of employees did not actually comprise teams, given their members' individualized and nonshared views on identity. As the hypothesis testing requires variables at the meso level, these teams were excluded from the sample.

After this verification, intergroup heterogeneity was investigated. The ICC values obtained in the present study, between 0.12 and 0.15 , proved to be in line with studies in the organizational field and indicate the presence of significant differences in magnitude between the teams participating in the study. The results of the one-way ANOVA revealed significant differences between the groups, confirming the occurrence of emergence in the study variables. Table I presents mean $\mathrm{AD}_{\mathrm{Md}}$ values, the ICC magnitude values and the oneway ANOVA results. Together, these data authorize the composition of group scores from information collected at the individual level.

Once the requirements for emergence of the variables were met, the individual scores were aggregated to the group level by the arithmetic mean. This strategy resulted in a 
sample of 101 teams for analysis. To carry out the analyses proposed in this work, the data representing the teams were gathered into a single database.

To verify the relationship between shared identity and effectiveness, three regression analyses were conducted using the stepwise method. Each one had the factors that represent work team identity (affective, cognitive and evaluative) as predictors, and as criterion variable, one of the indicators of effectiveness: work team satisfaction and performance (manager evaluations and objective performance indicators).

First, the statistical assumptions of the chosen technique were verified. Based on the criteria stipulated by Miles and Shevlin (2001), asymmetry values were below 2 in all variables $(-1.22<\times<0.64)$, meeting the assumption of normality. In all the equations, the examination of residuals made it possible to verify that the assumptions of multivariate normality, linearity and homoscedasticity and independence of errors were met.

The correlations between variables were also calculated (Table II). As they were elements of the same phenomenon, the components of work team identity, the predictive variables of the study, showed intermediate to strong correlations with one another $(0.48<\times<0.84 ; p<0.01)$. Multicollinearity diagnosis permits verification of the extent to which one variable is explained by the other. It is provided by the variance inflation factor (VIF) and the tolerance value. VIF values above 10 and tolerance values below 0.10 indicate multicollinearity (Hair et al., 2009). The VIF and tolerance values found were equal to 1 , that is, below the stipulated limits. Despite the correlations found, the cognitive, affective and evaluative components of identity can be treated as different predictors.

Once the regression assumptions had been investigated, the predictive model test was conducted. $H 1$ predicted that the affective component of work team identity is the main predictor of work team satisfaction. Retained in the first step of the regression, the affective component of work team identity showed the greatest predictive power, explaining

\begin{tabular}{lcccc}
\hline Variables & \multicolumn{2}{c}{$\mathrm{AD}_{\text {Md }}$} & \\
\hline Affective component of WTI & 0.15 & 0.49 & 0.30 & $F(130,236)=1.45^{*}$ \\
Cognitive component of WTI & 0.12 & 0.61 & 0.29 & $F(130,236)=1.36^{* *}$ \\
Evaluative component of WTI & 0.12 & 0.54 & 0.26 & $F(130,236)=1.65^{*}$ \\
Work team satisfaction & 0.14 & 0.40 & 0.25 & $F(130,236)=1.4^{*}$
\end{tabular}

Notes: $* p<0.01 ; * * p<0.001$

Team
effectiveness

(14)

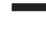

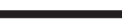


RAUSP

54,2

approximately 63 per cent of work team satisfaction $(B=0.79, p<0.01)$. The second block of retentions captured the cognitive factor, which, when incorporated into the predictive model, added approximately 7 per cent of explanation. The evaluative dimension did not attain sufficient values to be retained. The standardized beta values of the affective and cognitive factors ( $\beta=0.45 ; p<0.01$ and $\beta=0.43 ; p<0.01$, respectively) demonstrate the slightly superior power of the affective factor and confirm the relative importance of the affective aspect for satisfaction.

These findings reveal that by involving the positive feelings of the individual in relation to the group, the affective component of social identity contributes support for positive experiences and, consequently, satisfaction. Although to a lesser extent, the cognitive factor also demonstrated predictive power regarding satisfaction. The cognitive component of work team identity measures how much the individual perceives characteristics in common among other members of the group. The perception of similarity, in turn, favors the improvement of interpersonal relationships and can lead to positive feelings, such as satisfaction. These arguments explain the significance obtained.

$H 2$ and $H 3$ predicted that the evaluative component of work team identity is positively related to performance. In the present study, two performance criteria were used:

(1) An indicator adopted by the organization to evaluate the performance of its units (secondary data); and

(2) Performance evaluation handled by the manager.

Regarding the objective indicator of performance, none of the factors of work team identity attained significant results. Thus, $H 2$ was not supported with the data collected in this study. To explain this finding, we turn to the nature of the criterion. In generating descriptive measures, it is observed that mean performance is 112.90 and the SD, 3.75, which indicates a high degree of similarity in the responses. The low variability and high concentration of the criterion variable around the arithmetic mean certainly must have compromised its explanatory power, as the amount of variance to be explained was truly scant, and, consequently, it was less likely that predictors with significant effect would be found.

Continuing with the testing of the hypotheses, the impact of work team identity on the performance evaluation conducted by the managers (H3) was verified. In the single step predicted in the regression, only the evaluative factor was retained and explained 6 per cent of the performance evaluated by the immediate supervisor of the team $(B=0.26 ; p<0.05)$. It was found that the relationship between these variables is direct and positive, such that for each point gained in the value of the evaluation component, 0.26 of the performance evaluation is changed. These results allow us to infer that teams that make a favorable assessment of their group tend to demonstrate a better job performance. This finding becomes even more relevant if we consider that the data included in the prediction model under analysis came from different sources, which reduces the possibility of variance explained because of a common source. Thus, it can be argued that the identified association adequately reflects the phenomenon investigated.

Previous studies had not yet found any direct relationship between work team identity and team performance (Ellemers et al., 2013; Solansky, 2011; Swaab et al., 2008). The results found in the present study can be attributed to the prediction of the evaluative component of work team identity, as well as to sharing. As demonstrated, team assessment awareness, the evaluative component of social identity, contributes to team goals being seen as their own 
and having the power to guide the behavior of the team members. The similarity of interpretations intensifies the impact exerted by the evaluative component.

The hypotheses that guided this study posited specific particular relations between the dimensions of identity and several indicators of effectiveness. In general, the results obtained confirm the relationship between work team identity and different indicators of team effectiveness, which reinforces their importance in the functioning of work teams.

\section{Final considerations}

SIT aims to understand intergroup relations and comprehend how the group, when internalized, interferes in its members' behavior, cognitions and emotions. The findings seen here not only reinforce the importance of the identities constructed in the organizational context in explaining behavior and attitudes at work but also demonstrate the contribution of SIT for understanding the functioning and effectiveness of work teams. The results indicate that the way in which social identity is measured and represented reveals distinctions in the relationships between work team identity and different indicators of effectiveness. It could be inferred that this relationship depends on the level of correspondence between the components of identity and the criteria of work team effectiveness, as well as on the level at which these analyses are carried out.

In relation to work teams, it was found that the extent to which individuals, in a joint way, identify with their respective teams has an impact on the effectiveness of these work units. Work team identity, as a collective phenomenon, can be considered an element that unites individuals around team goals.

In bringing evidence of the impact of identity on the functioning of work teams, these findings offer important implications for team management and human resource policymaking. In this way, managers should seek forms of action and work organization that favor the development of team identity.

Although the affective and evaluative components may have appeared in a prevalent manner in the prediction models, it is important to emphasize that the development of these elements depends on the recognition of the individual as a member of the group. In this sense, the cognitive component becomes a central element of identity and must also be the object of intervention. Thus, strategies aimed at the creation and delimitation of the content of identity are equally relevant.

These results, however, do not exempt the study from limitations. One of them is related to the absence of variables antecedent to the formation or the sharing of team identity. Future research can invest effort in this direction and investigate antecedents to the components of work team identity, as well as factors that are involved in their sharing. The fact that the study was carried out in a single institution reduces the generalizability of the results for other contexts. Studies in different organizations could remedy this gap. The cross-sectional design of this study should also be recognized as a limitation. Thus, the temporal relations between the studied variables are assumed and not shown in fact.

Finally, we conclude that the objectives proposed for this work were satisfactorily achieved. We hope that it will have inspired researchers interested in understanding social identity and work team identity, so that further studies on the subject are developed. Likewise, we hope that the present study has attracted the attention of managers and team members to the centrality of this phenomenon so important for the effectiveness of work teams. 
RAUSP

54,2

\section{References}

Allen, N.J. and Hecht, T.D. (2004a), "The romance of the teams: towards an understanding of its psychological underpinnings and implications", Journal of Occupational and Organizational Psychology, Vol. 77 No. 4, pp. 439-461.

Allen, N.J. and Hecht, T.D. (2004b), "Further thoughts on the romance of the teams: a reaction to the commentaries", Journal of Occupational and Organizational Psychology, Vol. 77 No. 4, pp. 485-491.

Ashforth, B.E., Harrison, S.H. and Corley, K.G. (2008), "Identification in organizations: an examination of four fundamental questions", Journal of Management, Vol. 34 No. 3, pp. 325-374, doi: 10.1177/ 0149206308316059 .

Ashforth, B.E., Rogers, K.M. and Corley, K.G. (2011), "Identity in organizations: exploring cross-level dynamics", Organization Science, Vol. 22 No. 5, pp. 1144-1156.

Bliese, P.D., Chan, D. and Ployhart, R.E. (2007), "Multilevel methods: future directions in measurement, longitudinal analyses, and nonnormal outcomes", Organizational Research Methods, Vol. 10 No. 4, pp. 551-563, doi: 10.1177/1094428107301102.

Burke, M., J. and Dunlap, W.P. (2002), "Estimating interrater agreement with the average deviation (AD) index: a user's guide", Organizational Research Methods, Vol. 5 No. 2, pp. 159-172.

Chan, D. (1998), "Functional relations among constructs in the same content domain at different levels of analysis: a typology of composition models", Journal of Applied Psychology, Vol. 83 No. 2, pp. 34-246.

Ellemers, N., Kortekaas, P. and Ouwerkerk, J.W. (1999), "Self-categorization, commitment to the group self-esteem as related but distinct aspects of social identity", European Journal of Social Psychology, Vol. 29 Nos 2/3, pp. 371-389, doi: 10.1002/(LSICI)10990992(199903/05)29:2/3<371:: AID-EJSP932>3.0.CO;2-U.

Ellemers, N., Sleebos, E., Stam, D. and de Gilder, D. (2013), "Feeling included and valued: how perceived respect affects positive team identity and willingness to invest in the team", British Journal of Management, Vol. 24 No. 1, pp. 21-37.

Gunlach, M., Zivnuska, S. and Stoner, J. (2006), "Understand the relationship between individualismcollectivism and team performance through an integration of social identity theory and the social relations model", Human Relations, Vol. 59 No. 12, pp. 1603-1632, doi: https:/doi.org/ 10.1177/0018726706073193

Hackman, J.R. (1987), “The design of work teams”, in Lorsch, J.W. (Ed.), Handbook of Organizational Behavior, Prentice-Hall, Englewood Cliffs, NJ, 315-342.

Hair, J.F., Anderson, R.E., Tatham, R.L. and Black, W.C. (2009), Análise Multivariada de Dados, Bookman, Porto Alegre.

Johnson, M.D., Morgeson, F.P. and Hekman, D.R. (2012), "Cognitive and affective identification: exploring the links between different forms of social identification and personality with work attitudes and behavior", Journal of Organizational Behavior, Vol. 33 No. 8, pp. 1142-1167, doi: 10.1002/job.1787.

Johnson, M.D., Morgeson, F.P., Ilgen, D.R., Meyer, C. and Lloyd, J.R. (2006), "Multiple professional identities: examining differences in identification across work-related targets", Journal of Applied Psychology, Vol. 91 No. 2, pp. 498-506, doi: 10.1037/0021-9010.91.2.498.

Kozlowski, S.W.J. and Klein, K.J. (2000), "A multilevel approach to theory and research in organizations: contextual, temporal, and emergent processes", in Klein, KJ. and Kozlowski, S.W.J. (Eds), Multilevel Theory, Research and Methods in Organization: Foundations, Extensions and New Directions, Jossey-Bass, San Francisco, CA, pp. 3-90.

Miles, J. and Shevlin, M. (2001), Applying Regression and Correlation: A Guide for Students and Researchers, Sage, London.

Miscenko, D. and Day, D.V. (2016), "Identity and identification at work”, Organizational Psychology Review, Vol. 6 No. 3, pp. 215-247. 
Postmes, T., Haslam, S.A. and Swaab, R. (2005), "Social influence in small groups: an interactive model of social identity formation”, European Review of Social Psychology, Vol. 16 No. 1, pp. 1-42.

Puente-Palacios, K.E. and Borges-Andrade, J.E. (2005), "O efeito da interdependência na satisfação de equipes de trabalho: um estudo multinível”, Revista de Administração Contemporânea, Vol. 9 No. 3, pp. 57-78.

Puente-Palacios, K.E., Porto, J. and Martins, M.D.C. (2016a), “A emersão na articulação de níveis em psicologia organizacional e do trabalho”, Revista Psicologia, Organizações e Trabalho, Vol. 16 No. 4, pp. 358-366, doi: 10.17652/rpot/2016.4.12603.

Puente-Palacios, K.E., Martins, M.C.F. and Palumbo, S. (2016b), "Desempenho de equipes: evidências de validade de uma medida”, Psico-USF, Vol. 21 No. 3, pp. 513-525, doi: 10.1590/141382712016210306.

Reis, D.P. and Puente-Palacios, K.E. (2016), "Identidade com equipes de trabalho: teoria e medida", Estudos de Psicologia, Vol. 21 No. 2, pp. 167-178, doi: 10.5935/1678-4669.20160017.

Riketta, M. and Van Dick, R.V. (2005), "Foci of attachment in organizations: a meta-analytic comparison of the strength and correlates of workgroup versus organizational identification and commitment", Journal of Vocational Behavior, Vol. 67 No. 3, pp. 490-510.

Salas, E., Shuffler, M.L., Thayer, A.L., Bedwell, W.L. and Lazarra, E.H. (2015), "Understanding and improving teamwork in organizations: a scientifically based practical guide", Human Resource Management, Vol. 54 No. 4, pp. 599-622, doi: 10.1002/hrm.21628.

Siqueira, M.M.M. and Gomide, S. Jr (2014), "Vínculos do indivíduo com o trabalho e com a organização", in Zanelli, J.C., Borges-Andrade, J.E. and Bastos, A.V.B. (Eds), Psicologia, Organizações e Trabalho No Brasil, 2a. Edição., Artmed, Porto Alegre, pp. 300-330, pp. 316-349.

Solansky, S.T. (2011), "Team identification: a determining factor of performance", Journal of Managerial Psychology, Vol. 26 No. 3, pp. 247-258.

Swaab, R.I., Postmes, T. and Spears, R. (2008), "Identity formation in multiparty negotiation", British Journal of Social Psychology, Vol. 47 No. 1, pp. 167-187.

Tajfel, H. (1982), "Social psychology of intergroup relations", Annual Review of Psychology, Vol. 33 No. 1, pp. 1-39.

Tajfel, H. and Turner, J.C. (1979), “An integrative theory of intergroup behavior”, in Austin, W.G. and Worchel, S. (Eds), The Social Psychology of Intergroup Relations, Brooks/Cole, Monterey, CA, pp. 33-47.

Turner, J.C., Hogg, M.A., Oakes, P.J., Reicher, S.D. and Wetherell, M.S. (1987), Rediscovering the Social Group: A Self-Categorization Theory, Blackwell, Oxford.

Van Dick, R., Wagner, U., Stellmacher, J. and Christ, O. (2004), "The utility of a broader conceptualization of organizational identification: which aspects really matter?", Journal of Occupational and Organizational Psychology, Vol. 77 No. 2, pp. 171-191, doi: 10.1348/ 096317904774202135.

Van Knippenberg, D. and Van Schie, E.C.M. (2000), "Foci and correlates of organizational identification", Journal of Occupational and Organizational Psychology, Vol. 73 No. 2, pp. 137-147, doi: $10.1348 / 096317900166949$.

\section{Corresponding author}

Daniela Pinheiro dos Reis can be contacted at: danielarei@gmail.com

Associate editor: Renata Schrrmeister

For instructions on how to order reprints of this article, please visit our website:

www.emeraldgrouppublishing.com/licensing/reprints.htm

Or contact us for further details: permissions@emeraldinsight.com 